\title{
A prospective study of safety, efficacy and acceptability of postpartum insertion of intrauterine contraceptive device in a tertiary care hospital in Maharashtra, India
}

\author{
Nandkishor B. Gaikwad, Poornima M.*, Atul Lipare
}

Department of Obstetrics and Gynecology, Government Medical College and Hospital, Miraj, Maharashtra, India

Received: 16 May 2020

Accepted: 10 June 2020

*Correspondence:

Dr. Poornima M.,

E-mail: poornialias@gmail.com

Copyright: () the author(s), publisher and licensee Medip Academy. This is an open-access article distributed under the terms of the Creative Commons Attribution Non-Commercial License, which permits unrestricted non-commercial use, distribution, and reproduction in any medium, provided the original work is properly cited.

\begin{abstract}
Background: IUCD (intrauterine contraceptive device) to prevent pregnancy are among the oldest method of contraception. The modern IUCD are highly effective, safe private, long acting and rapidly reversible contraceptive method. Aims and objective of this study was to study the acceptability and safety of postpartum intrauterine contraceptive device (PPIUCD) in postpartum period and to assess the feasibility, safety, efficacy and expulsion rate of IUCD.

Methods: A prospective observational study was conducted at tertiary care teaching hospital in Maharashtra from January 2018 to October 2018 and patients were followed up to a period of one-year post IUCD insertion.

Results: Majority of patients in this study were in age group 21 to 26 years of age $(58.7 \%)$ and the least number were in the age group more than 30 years $(3.3 \%)$. This study showed that majority of patients were primigravida (44\%) and the lowest number belonged to gravida $6(0.3 \%)$. Regarding timing of IUCD insertion $73 \%$ were done intra caesarean, $22.3 \%$ were done post placental and $4.7 \%$ were done within 48 hours of delivery. In this study authors found that $4 \%$ of patients had per vaginal discharge, $5 \%$ had missing IUCD thread and $2 \%$ of patients had IUCD expulsion. It was found in this study that $98 \%$ of patients continued to use IUCD and only $2 \%$ discontinued the usage.

Conclusions: From the study authors came to conclusion that PPIUCD insertion is a safe, feasible, effective and reversible method of contraception.
\end{abstract}

Keywords: Contraception, Efficacy, Postpartum intrauterine contraceptive device, Primigravida

\section{INTRODUCTION}

India population has crossed one billion in the year 2000 . In the census of 2011, it has reached 121 crores and it is estimated to reach a figure of 1.53 billion by 2050 making India the most populous country in the world. ${ }^{1,2}$

National population policy of India was formulated in 2000 with long term objective of achieving a stable population by 2045 , at level consistent with requirement of sustainable economic growth and social development. One of the immediate objectives is to address the unmet need of contraception. A large proportion of woman in the postpartum period want to accept a contraceptive method to regulate their fertility, either by spacing or limiting future pregnancy. ${ }^{3}$

IUCD are among the most commonly used reversible method of contraception in women of reproductive age group worldwide. One in five (153 million) married contraceptive users are using IUCDs. ${ }^{4}$

PPIUCD appears as an ideal method for spacing births. Hence this study was undertaken keeping aims and objectives to prevent higher risk of adverse outcomes like postpartum haemorrhage, premature labour, low birth 
weight babies and maternal death due to unintended pregnancies.

\section{Aims}

To study the acceptability and safety of use of intrauterine contraceptive device in postpartum period.

\section{Objectives}

To assess the feasibility, safety, efficacy and expulsion rate of IUCD insertion in postpartum period.

\section{METHODS}

This is a prospective observational study conducted at a tertiary care teaching medical college and hospital in Maharashtra. All postpartum patients who are willing to use IUCD for contraception in post-partum period were included in this study from January 2018 to October 2018 and patients were followed-up up to a period of one-year post IUCD insertion for the study.

\section{Inclusion criteria}

- All patients who are eligible and willing for insertion of IUCD in postpartum period were included in the study.

\section{Exclusion criteria}

- Patients who had the following conditions were excluded from the study,

- Pregnant patients who were below 28 weeks gestation, fever, genital tuberculosis, anaemia, PPH (postpartum hemorrhage), obstructed labour, uterine fibroids, PROM $>12$ hours, history of ectopic pregnancy in the past, HIV positive patients and those who had uterine anomalies or genital cancer.

\section{Patient selection}

All pregnant woman delivered beyond 28 weeks gestation at tertiary care teaching medical hospital and college in Maharashtra from January 2018 to October 2018 were included in the study.

\section{Sample size}

In this study 750 patients were counselled for postpartum IUCD insertion, out of which 300 patients accepted and were followed up for one-year post IUCD insertion.

In this study copper T 380A was used.

\section{Follow-up}

Follow-up of the patient is vital component of this study. After PPIUCD insertion woman are advised routine postpartum care up to 6 weeks, and they were asked to return after 6 months and then after one year for assessment of acceptability. During follow-up complete clinical check-up, speculum examination was performed to see IUCD thread and any vaginal discharge. Those patients who did not come for follow-up were contacted on phone and enquired regarding any complaint's ad complications about of copper $\mathrm{T}$ insertion.

\section{Safety analysis}

It was done on the basis of patient's complaints like pain in abdomen, excessive vaginal bleeding, foul smelling vaginal discharge.

\section{Efficacy analysis}

In view of expulsion rate and continuation rate at followup visit.

\section{Statistical analysis}

Data was entered in Microsoft excel data sheet and was analysed using SPSS22 version software. Categorical data was represented in the form of frequencies and proportions. Chi square was used as test of significance for qualitative data, continues data was represented as mean and standard deviation.

\section{Graphical representation of data}

Microsoft excel and Microsoft word was used to obtain graphs and charts. $\mathrm{p}$ value (probability that the result is true) of $<0.05$ is considered as statistically significant after assuming all the rules of statistical tests.

\section{RESULTS}

Majority of patients in this study were in age group 21 to 26 years of age $(58.7 \%)$, followed by those who were below 20 years of age $(22.7 \%)$ and the least number were in the age group more than 30 years $(3.3 \%)$ (Table 1$)$.

Table 1: Age distribution of patients.

\begin{tabular}{|lll|}
\hline Age & Number of patients & Percentage \\
\hline$<20$ years & 68 & $22.7 \%$ \\
\hline $21-25$ years & 176 & $58.7 \%$ \\
\hline 26 -30 years & 46 & $15.3 \%$ \\
\hline$>30$ years & 10 & $3.3 \%$ \\
\hline Total & 300 & $100 \%$ \\
\hline
\end{tabular}

This study showed that majority of patients were primigravida (44\%) ad $40 \%$ were second gravida patients, the lowest number belonged to gravida $6(0.3 \%)$ (Figure 1).

The counselling for use of IUCD was given to patients mostly during early labour $(76.7 \%)$ and the remaining patients were counselled antenatally $(23.3 \%)$ (Table 2). 


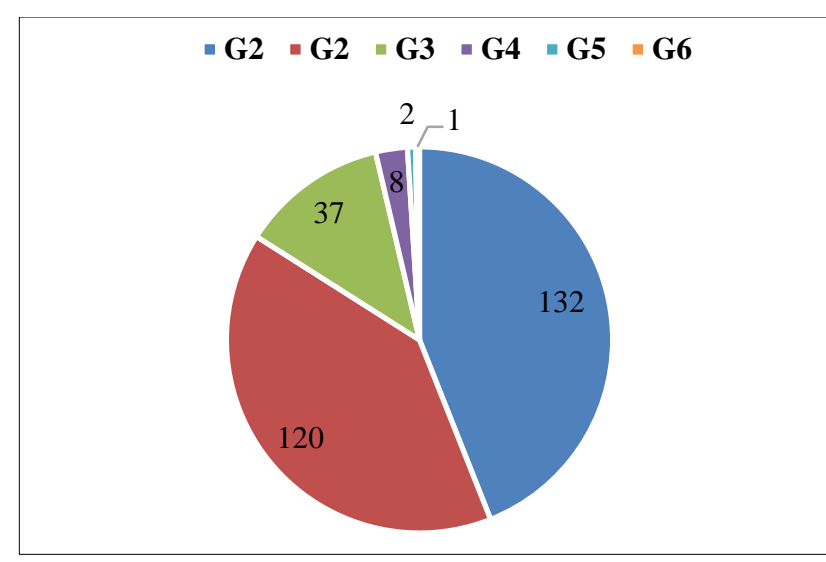

Figure 1: Gravida distribution of patients.

Table 2: Type of counselling done for patients.

\begin{tabular}{|lll|}
\hline & Number of patients & Percentage \\
\hline Antenatal & 70 & $23.3 \%$ \\
\hline Early labour & 230 & $76.7 \%$ \\
\hline Total & 300 & $100 \%$ \\
\hline
\end{tabular}

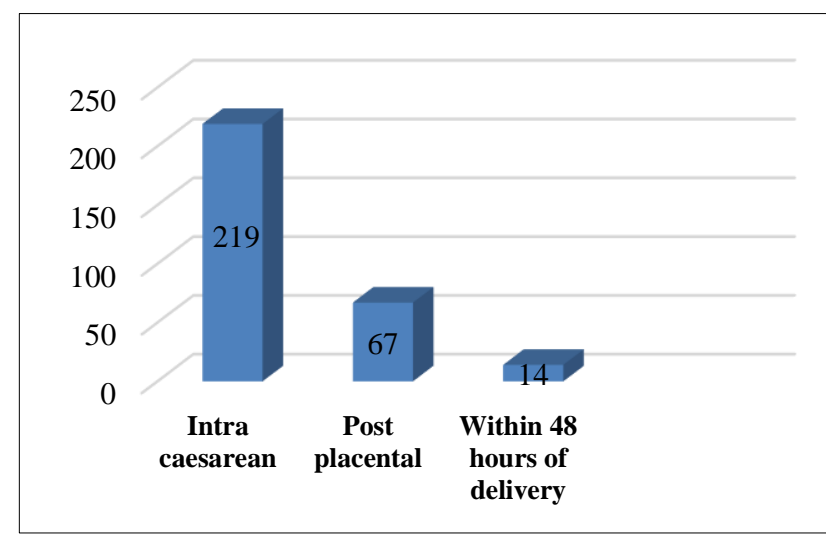

Figure 2: Time of insertion of IUCD among patients.

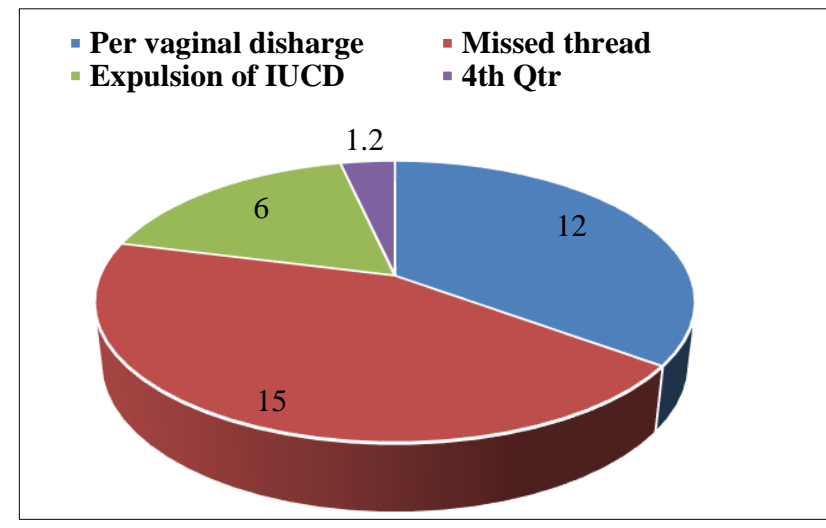

Figure 3: Complications of IUCD insertion among patients.

Regarding timing of IUCD insertion $73 \%$ were done intra caesarean, $22.3 \%$ were done post-placental and $4.7 \%$ were done within 48 hours of delivery (Figure 2).
The patients were asked to come for follow-up post IUCD insertion. $41 \%$ of patients came for follow-up at 6 weeks post IUCD insertion, $70 \%$ came for follow up after 6 months and $58.7 \%$ came after one year (Table 3 ).

Table 3: Distribution based on follow-up of patients after IUCD insertion.

\begin{tabular}{|llll|}
\hline & & Number of patients & Percentage \\
\hline After 6 & No & 177 & $59 \%$ \\
\cline { 2 - 4 } weeks & Yes & 123 & $41 \%$ \\
\hline After 6 & No & 90 & $30 \%$ \\
\cline { 2 - 4 } months & Yes & 210 & $70 \%$ \\
\hline After 1 & No & 124 & $41.3 \%$ \\
\cline { 2 - 4 } year & Yes & 176 & $58.7 \%$ \\
\hline
\end{tabular}

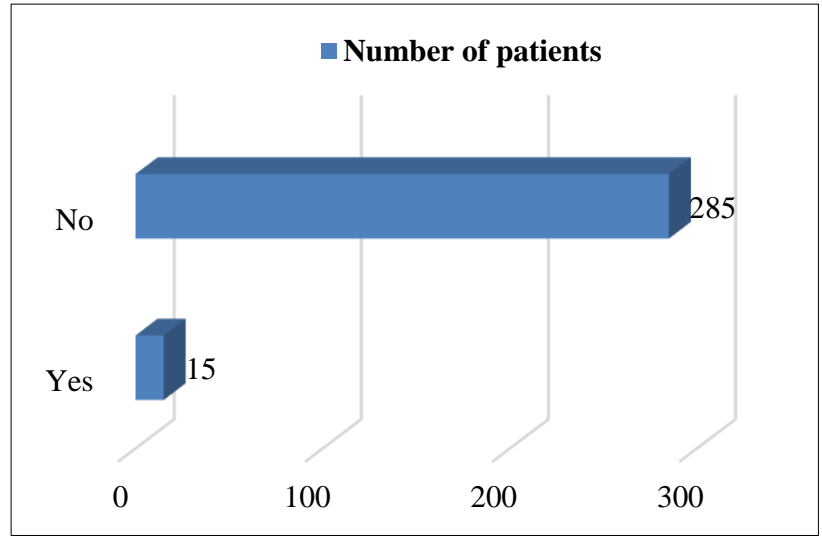

Figure 4: Distribution of patients based on per vaginal bleeding.

In this study authors found that $4 \%$ of patients had per vaginal discharge, 5\% had missing IUCD thread and $2 \%$ of patients had IUCD expulsion (Figure 3).

Out of all patients only 5\% had per vaginal bleeding (Figure 4).

It was found in this study that $98 \%$ of patients continued to use IUCD and only $2 \%$ discontinued the usage (Figure $5)$.

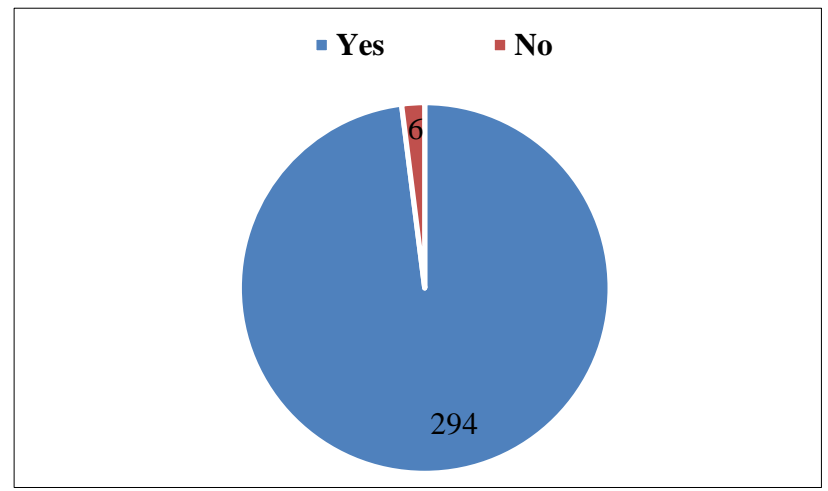

Figure 5: Distribution of cases based on continued use of IUCD. 
Table 4: Association between time of insertion and complication.

\begin{tabular}{|c|c|c|c|c|c|c|c|c|}
\hline & & \multicolumn{6}{|c|}{ Time of insertion of IUCD } & \multirow[t]{2}{*}{ p value } \\
\hline & & \multicolumn{2}{|c|}{ Intra caesarean } & \multicolumn{2}{|c|}{ Post placental } & \multicolumn{2}{|c|}{ Within 48 hours of delivery } & \\
\hline & & Number & Percentage & Number & Percentage & Number & Percentage & \\
\hline \multirow{2}{*}{$\begin{array}{l}\text { Per vaginal } \\
\text { bleeding }\end{array}$} & No & 206 & $94.1 \%$ & 65 & $97 \%$ & 14 & $100 \%$ & 0.425 \\
\hline & Yes & 13 & $5.9 \%$ & 2 & $3 \%$ & 0 & $0 \%$ & \\
\hline \multirow{2}{*}{$\begin{array}{l}\text { Per vaginal } \\
\text { discharge }\end{array}$} & No & 211 & $96.3 \%$ & 64 & $95.5 \%$ & 13 & $92.9 \%$ & 0.791 \\
\hline & Yes & 8 & $3.7 \%$ & 3 & $4.5 \%$ & 1 & $7.1 \%$ & \\
\hline \multirow{2}{*}{ Missed thread } & No & 209 & $95.4 \%$ & 62 & $9.5 \%$ & 14 & $100 \%$ & 0.432 \\
\hline & Yes & 10 & $4.6 \%$ & 5 & $7.0 \%$ & 0 & $0 \%$ & \\
\hline \multirow{2}{*}{$\begin{array}{l}\text { Expulsion of } \\
\text { IUCD }\end{array}$} & No & 216 & $98.6 \%$ & 64 & $5.5 \%$ & 14 & $100 \%$ & 0.243 \\
\hline & yes & 3 & $1.4 \%$ & 3 & $4.5 \%$ & 0 & $0 \%$ & \\
\hline
\end{tabular}

Table 5: Association between time of insertion and continuation of IUCD.

\begin{tabular}{|c|c|c|c|c|c|c|c|}
\hline & & \multicolumn{2}{|c|}{ Intra caesarean } & \multicolumn{2}{|c|}{ Post placental } & \multicolumn{2}{|c|}{ Within 48 hours of delivery } \\
\hline & & Number & Percentage & Number & Percentage & Number & Percentage \\
\hline \multirow{2}{*}{$\begin{array}{l}\text { Continued } \\
\text { use of IUCD }\end{array}$} & Yes & 215 & $98.2 \%$ & 66 & $98.5 \%$ & 13 & $92.9 \%$ \\
\hline & No & 4 & $1.8 \%$ & 1 & $1.5 \%$ & 1 & $7.1 \%$ \\
\hline
\end{tabular}

$\mathrm{X}^{2}=2.011, \mathrm{df}=1, \mathrm{p}=0.366$.

There was no significant difference in complication rates between time of insertion of IUCD. Per vaginal bleeding was common in intra-caesarean insertion. Per vaginal discharge was common in IUCD insertion within 48 hours of delivery, missed thread and expulsion of $\mathrm{Cu} \mathrm{T}$ were commonly seen in post-placental insertion (Table $4)$.

There was no significant difference in discontinuation of IUCD and time of insertion. Continuation rate was highest for intra caesarean IUCD and lowest for those who had IUCD insertion within 48 hours of delivery (Table 5).

\section{DISCUSSION}

\section{Acceptability}

In this study 750 patients were counselled for postpartum IUCD insertion, out of which $40 \%$ of patient accepted the procedure. Most of them did not accept due to lack of awareness of contraceptive and fear of complications. The reason for acceptance was it was a reversible method of contraception. Mule et al in her study found that the acceptance rate increases with at least one living child $(31.5 \%)$ and with second child $(55 \%){ }^{5}$ Kittur $\mathrm{S}$ et al who conducted a study in Karnataka where 850 subjects were screened out of which $210(24.7 \%)$ accepted PPIUCD. ${ }^{6}$ Khamis et al, who conducted a study on PPIUCD in elective LSCS patients out of the 237 patients for elective LSCS, 86 accepted for intra caesarean placement of IUCD and 151 $(63.7 \%)$ declined which was similar to this study. ${ }^{7}$
Mule et al in her study $72.5 \%$ of patients accepted for intra caesarean method, $22.5 \%$ for post placental method and only $5 \%$ accepted for postpartum method which is similar to this study. ${ }^{5}$

\section{Demography}

In this study most of the patients who accepted PPIUCD here between 21 to 25 years $(58.7 \%)$ and the number was least among patients <30 years of age (3.3\%). As per study by Gupta A et al majority acceptance rate was between $20-25$ years. $^{8}$ A total $44 \%$ of patients were primipara and $40 \%$ were multipara. Acceptance was higher among primipara which help them for proper spacing of birth. While patients who are having more than 2 children preferred to use permanent method of sterilization.

\section{Follow-up}

In this study 21 patients $70 \%$ came for follow up at months and $123(41 \%)$ came at 6 weeks post IUCD insertion. Authors had high follow up rate at 6 weeks and 6 months. Those who failed to come for follow up were called and complaints regarding complications. Shukla et al, study 137 woman were undergoing post placental IUCD insertion out of them 280 did not come for followup, remaining $1037(78.7 \%)$ came after 6 weeks and 11 of $1037(11.37 \%)$ came for second follow-up after 6 months of delivery. ${ }^{9}$ Kabadi YM and Kittur S conducted a study were 850 subjects screened, 210 accepted for insertion, there $3.8 \%$ who were not came for follow-up. After telephonic conversation and sending messages $4.28 \%$ of subject had an early follow-up. ${ }^{6}$ 


\section{Safety}

For assessment of safety of PPIUCD authors asked about the complaints like pv bleeding, pv discharge and pain abdomen, fever. In this study only $5 \%$ patients had per vaginal bleeding pv. Gupta A et al who conducted a study in western Uttar Pradesh hospital had $8 \%$ of patients with per vaginal bleeding. ${ }^{8}$

\section{Efficacy}

As per study conducted by Haldar A et al at NRS Medical College, Kolkata expulsion rate was $4 \%$ after post placental vaginal insertion and $2 \%$ after postplacental caesarean insertion. ${ }^{10}$ In this study the expulsion rate after post placental vaginal and post placental caesarean was the same. In a study by Bhatt $\mathrm{S}$ et al the expulsion rate was $8.54 \%$ which was more than insertion. ${ }^{11}$ Khamis et al studied the expulsion rate and continuation rate in 86 patients. Expulsion rate was 1 $(1.4 \%)$ and discontinuation rate was $4(5.6 \%)$ by the end of 6 weeks. $^{7}$ In this study discontinuation rate was $2 \%$ and the reason was pv bleeding, but after counselling they accepted other methods of contraception.

\section{CONCLUSION}

From the study authors come to a conclusion that PPIUCD insertion is safe, feasible, cost effective, and reversible method of contraception. As most of the patients do not come for routine follow-up, if they are made to wait for 6 weeks before starting any effective contraceptive there are chances of accidental pregnancies, hence this method is most applicable in our country.

The PPIUCD also offers an alternative method to sterilization for patient with low parity but not keen on further child baring. It helps us to prevent adverse outcomes of unintended next pregnancies like preterm birth, low birth weight babies, abortion and postpartum hemorrhage. This study supports the Government of India guidelines that PIUCD should be part of every hospital family welfare program to give maximum benefit to the patients.

All healthcare personnel including ANM, staff nurse and doctors should be rained to give proper counselling regarding PPIUCD and its benefits, so that patient can make an informed decision regarding contraception.

Funding: No funding sources

Conflict of interest: None declared
Ethical approval: The study was approved by the Institutional Ethics Committee

\section{REFERENCES}

1. Majhi AK. Importance of PPIUCD in perspective of present Indian population scenario. Indian J Perinatol Reprod Biol. 2012;2(2):5-7.

2. IUCD reference manual for medical officers, Family Planning Division, Ministry of Health and Family Welfare, Government of India. 2007;1:1-20.

3. Postpartum IUCD reference manual by family planning division, Ministry of Health and Family Welfare, Government of India; 2010:2-6.

4. Salem R. New attention to IUD: Expanding women's contraceptive option to meet their needs: population report: series B, no. 7, John Hopkins Boomberg school for public health, the INFO project, Baltimore; 2006:1-26.

5. Mmule VD, Rhokade JV. Study the efficacy and compliance of postpartum intra uterine device. Medpulse Int J Gynaecol. 2017;3(2):91-5.

6. Kittur S, Kabadi YM. Enhancing contraceptive usage by postplacental intrauterine contraceptive device insertion with evaluation of safety, efficacy and expulsion. Int J Reprod Contracept Obstet Gynecol. 2012;1(1):2632.

7. Ballith K. Acceptability, uptake and safety of intra operative IUCD placement at $\mathrm{KNH}$ and Pumwani Maternity hospital. Available at: http:/erepository .uonbi.ac.ke:8080/xlui/handle/12345778/178/dated 2012. Accessed on $12^{\text {th }}$ April 2020.

8. Gupta A, Verma A, Chauhan J. Evaluation of PPIUCD versus interval IUCD (380A) insertion in teaching hospital of western Uttar Pradesh. Int J Reprod Contracept Obstet Gynecol. 2013;2(2):294-8.

9. Shukla M, Chandrawati S. Postplacental intrauterine device insertion - a five-year experience at tertiary care centre in north India. Indian $\mathrm{J}$ Med Res. 2012;16(3):432-5.

10. Halder A, Sowmya MS, Gayen A, Bhattacharya P, Mukherjee S, Datta S. A prospective study to evaluate vaginal insertion and intra-cesarean insertion of post-partum intrauterine contraceptive device. J Obstet Gynecol India. 2016;66(1):35-41.

11. Bhat SS, Damle H, Darawade SP, Junnare K, Ashturkar M. To study the acceptance of postpartum intrauterine contraceptive device, CU T $380 \mathrm{~A}$, in a tertiary care hospital in India. J Reprod Health Med. 2016;2(2):93-8.

Cite this article as: Gaikwad NB, Poornima M, Lipare A. A prospective study of safety, efficacy and acceptability of postpartum insertion of intrauterine contraceptive device in a tertiary care hospital in Maharashtra, India. Int J Reprod Contracept Obstet Gynecol 2020;9:3037-41. 